\title{
sciendo
}

DOI: 10.1515/adms-2017-0028

\author{
A. K. Krella ${ }^{1}$, D. E. Zakrzewska ${ }^{1,2}$ \\ ${ }^{1}$ Institute of Fluid Flow Machinery, Polish Academy of Sciences, Fiszera 14, \\ 80-231 Gdansk, Poland \\ ${ }^{2}$ Gdańsk University of Technology, Interdisciplinary Doctoral Studies, Narutowicza, 11/12 \\ 80-233 Gdansk, Poland \\ akr@imp.gda.pl
}

\section{CAVITATION EROSION - PHENOMENON AND TEST RIGS}

\begin{abstract}
The cavitation and cavitation erosion phenomenon have been shortly presented. The main four types of test rigs to investigate the cavitation erosion resistance have been shown. Each type of test design is described and an example of a design is shown. A special attention has been payed to the designs described in the International ASTM Standards: a vibratory design and a cavitating jet cell. There was shown that the design of a test device and the test conditions affect the resistance to cavitation erosion of a material.
\end{abstract}

Keywords: cavitation, cavitation erosion, test rig

\section{INTRODUCTION}

Cavitation phenomenon is defined as the process of development and growth of vapor bubbles in fast flowing liquid due to a rapid pressure drop, and then implosions of bubbles at the time of liquid pressure increase [1-6]. During bubble implosion shock wave and micro-jet are formed. Factors contributing to the phenomenon are: flow rate, pressure drop, temperature and chemical activity of liquid and content of dissolved gases or steam in the liquid [2-8]. Degradation of materials caused by the multiple impacts of shock waves and micro-jets is called cavitation erosion.

The cavitation erosion phenomenon is the major problem confronting designers and users of high-speed hydrodynamic system. It occurs mostly in fluid-flow machinery, for example pumps, water turbines, marine propellers, also in devices in the chemical and petrochemical industries, in diesel engines and pipelines [1-7]. Cavitation erosion is a reason of a drop of efficiency, an increase of noise and a decrease of service life of the systems [2-4,6]. Therefore, an interest of investigations of materials resistant to cavitation erosion remains at high level from many years.

In order to prevent materials against cavitation degradation, investigations of factors influencing the material resistance and methods of prediction of the material degradation rate have been performed. For that reason and in order to better understand the cavitation erosion 
phenomenon, several types of test rigs have been designed. Some of them have been described in International ASTM Standards. The aim of this paper is to present the main types of the test rigs in investigating material resistance against cavitation erosion. Additionally, in order to better understand the design of test rigs, cavitation phenomenon and cavitation erosion phenomenon have been also shortly presented.

\section{CAVITATION PHENOMENON}

Cavitation is a complex phenomenon, to which many investigations and publications have been devoted. The most important ones are the works of Knapp et al. [9], Brennen [6] Lauterbourn et al. [10-12] and the most recent one edited by Kim et al. [13]. Cavitation occurs in fast flowing liquid through a barricade that causes rapid pressure decrease below the critic pressure and violent formation of bubbles from undissolved gases in a liquid. The gas contained in the cavitation bubbles contributes to the formation of new cavities after their implosion, which can be repeated many times. Therefore, the content of gases in a liquid plays an essential role in cavitation initiation and development. Knapp et al [9] have showed that in a cavitation cloud are typically $10^{9}-10^{14}$ cavitation nuclei and there is correlation between the number and diameter of cavitation nuclei: along with a radius decrease the number of nuclei increases. Along with the liquid flow the bubbles move from the low pressure area to the high pressure area, which causing their implosion. The implosion of bubbles generates shock waves and liquid micro-jets.

In order to compare the state of cavitation development is used so-called cavitation number, which represents the probability of cavitation occurrence in a flowing stream of liquid. The cavitation number, $\sigma$, is determined by following equation:

$$
\sigma=\frac{p_{0}-p_{v}}{\frac{1}{2} \rho V_{0}^{2}}
$$

where:

$\mathrm{p}_{0}$ - static pressure in the stream in an undisturbed state,

$\mathrm{p}_{v}$ - vapor pressure,

$\rho$ - liquid density,

$\mathrm{v}_{0}$ - undisturbed stream velocity.

With decrease of cavitation number cavitation moves to more developed state and becomes more severe.

Lindau and Lauterborn [11] proposed a division of cavitation into cavitation caused by tension or by energy deposition (Fig. 1). He said that "hydrodynamic and acoustic cavitation are the result of tensions prevailing in a liquid, while optic and particle cavitation are the consequence of local deposition of energy." According to this division, hydrodynamic cavitation occurs due to rapture of liquid caused by pressure variation in flowing liquid. This type of cavitation is an essential problem in most hydraulic machinery. Next type of cavitation is acoustic cavitation, which is caused by pressure drop in a liquid resulting from propagation of acoustic wave. These two types of cavitation, hydraulic and acoustic cavitation, are used in their study of the phenomenon of cavitation erosion. In optic cavitation, high-intensity light, e.g. laser, is used to rupture a liquid and produce cavities due to delivering necessary intensity and energy in a very short time. This type of cavitation is used 
to study dynamic of cavitation bubble evolution. The last type of cavitation, particle cavitation is generated by elementary particle that rupture a liquid.

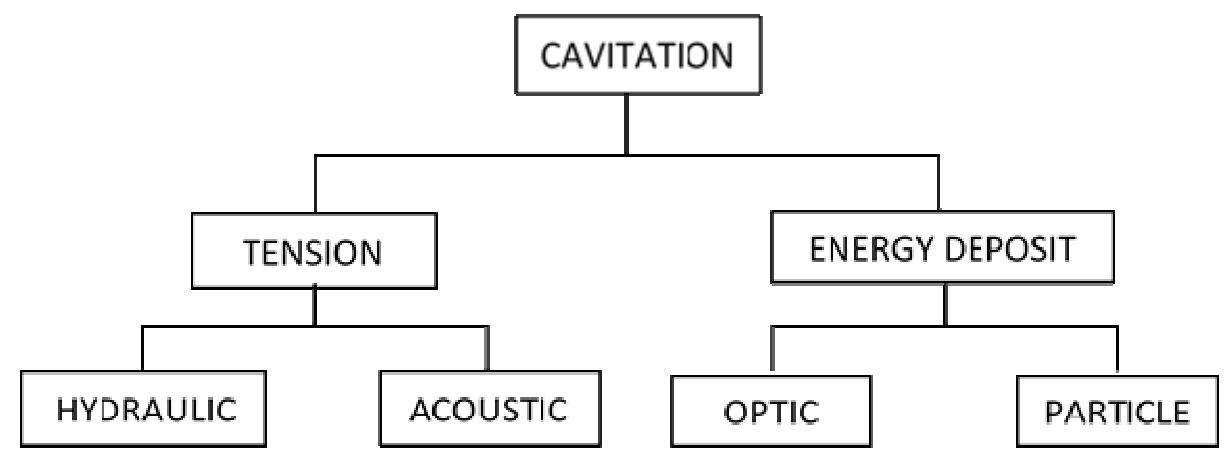

Fig. 1. Cavitation classification (Lauterborn) [11]

\section{CAVITATION EROSION PHENOMENON}

Cavitation erosion is a complex phenomenon of material degradation caused by implosion of cavitation bubbles in vicinity of solid surface. The size of loaded area, kinetic energy, rate of loading, temperature and frequency of loading have an effect on material degradation.

Due to cyclic loading the complex stress distribution arises in the surface layer that undergoes deformation. An increase of stress is time dependent and is determined by power and number of loading. If stress exceeds the material endurance cracks are generated and developed leading to removal of material particle. Thus, the cavitation erosion is time depend and is a kind of fatigue-like damage. In order to uniform the description of material degradation and test results, terminology related to cavitation and cavitation erosion is covered by the ASTM G-40 Standard. The most common way of presenting the results of material degradation caused by cavitation erosion is using graphs with cavitation curves that show an increase of cumulative volume or mass loss in time or graphs showing the correlation between cumulative mass or volume loss rate and exposure time (Fig. 2).

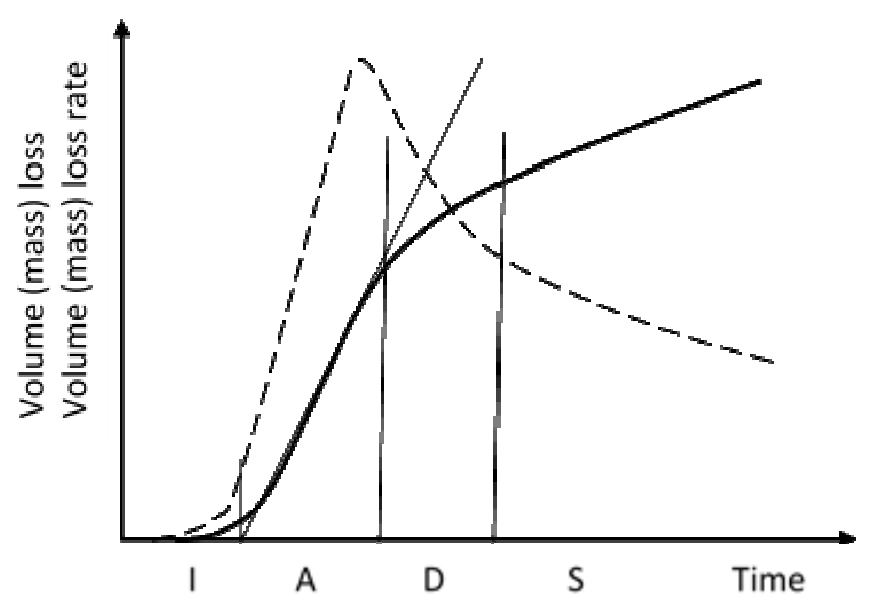


Fig. 2. Cavitation curves with showed periods of degradation. solid line - correlation of volume loss in exposure time, dashed line - correlation of volume loss rate in exposure time

According to ASTM G-32 Standard, material degradation and cavitation curve is divided into four periods: incubation (I), acceleration (A), deceleration (D) and steady state (S) (Fig. 2). At the beginning of material degradation occurs the incubation period, during which material loss is imperceptible small or non-measurable, properties of the surface layer are changed, plastic deformation in the form of pit and microcracks are created. These processes are the result of accumulation of impact energy by the material in the surface layer [1,2,4-6]. The next period is the acceleration period, in which occurs intensive material loss. This time interval the erosion rate increases to a maximum value. Accelerated degradation of the surface leads to change of surface geometry that causes start the next degradation period - the deceleration period. The last period of degradation is steady state period, during which the erosion rate is almost constant [1-7]. It should be added that the rate of material loss depend on material properties and on intensity of load, which is influenced by test rig design.

In order to describe degradation of materials caused by cavitation erosion, several parameters are proposed in ASTM Standards. The most important are: incubation period, mean depth of erosion penetration, MDE (also known as mean depth of penetration, MDP) and mean depth of penetration rate, MDPR. According to ASTM G-32 Standard, mean depth of erosion is "the average thickness of material eroded from a specified surface area, usually calculated by dividing the measured mass loss by the density of the material to obtain the volume loss and dividing that by the area of the specified surface":

$$
M D E=\frac{\Delta m}{\rho A}
$$

where:

$\Delta \mathrm{m}$ is mass loss, $\rho$ is density of the specimen,

A is referenced area of specimen.

MDPR is the rate of average eroded material volume loss per unit of exposed area. MDPR is inversely proportional to the ultimate resilience of the material. MDPR is related with mean depth of erosion penetration and defined by:

where:

$$
M D P R=\frac{M D E}{t}
$$

$t$ is exposure time.

\section{CAVITATION EROSION RIGS}

In investigation of cavitation erosion resistance of materials the most important factor is ensuring condition repeatability. Depending on the method of generating cavitation, the test devises can be divided into four main types of design [5,9,13,15-18]:

1. Vibratory apparatus;

2. Cavitating liquid jets.

3. Cavitation tunnels.

4. Rotating disc apparatus. 
The vibratory and cavitating jet apparatus are described in the ASTM G-32 and ASTM G-134 Standards.

\section{Vibratory apparatus}

A vibratory apparatus is the most popular device in testing cavitation erosion resistance [15-24]. Cavitation is generated by oscillating horn. Depending on location of a specimen, there are two types of devices: with a vibrating or a stationary specimen (Fig. 3), called the direct and the indirect method, respectively.

The ASTM G-32 Standard concerns the direct method, in which a specimen is attached to a vibrating horn. The device consists of the vessel containing the test liquid, horn, transducer and power supply (Fig. 3a). The vessel is cylindrical, and the depth of liquid in it shall be 100 $\pm 10 \mathrm{~mm}$. The immersion depth of the specimen test surface shall be $12 \pm 4 \mathrm{~mm}$. The vibrations are generated by a magnetostrictive or piezoelectric transducer. The frequency of oscillation is required to be $20 \pm 0.5 \mathrm{kHz}$ and the peak-to-peak displacement amplitude of the test surface of the specimen shall be $50 \mu \mathrm{m} \pm 5 \%$. In case of weak materials, the peak-to-peak displacement amplitude can be $25 \mu \mathrm{m}$. However, besides the devices that respect the ASTM Standard, there are also the rigs, which work with different than mentioned frequency and the peak-to-peak displacement amplitude. Investigations performed in International Cavitation Test [15] showed that frequency and the peak-to-peak displacement amplitude have an effect on generated cavitation intensity. With a decrease of those parameters, cavitation intensity and erosion rate decrease, for example: a decrease of the peak-to-peak amplitude from $50 \mu \mathrm{m}$ to $32 \mu \mathrm{m}$ caused a decrease of maximum depth penetration rate (MDPR) from $6.1 \mu \mathrm{m} / \mathrm{min}$ to $0.98 \mu \mathrm{m} / \mathrm{min}$ for AlMg2 aluminium alloy or from $0.45 \mu \mathrm{m} / \mathrm{min}$ to $0.043 \mu \mathrm{m} / \mathrm{min}$ for 1H18N9T austenitic stainless steel [15]

In case of the device with a stationary specimen - the indirect method of investigation of cavitation erosion, a specimen is located under the horn (Fig. 3b). Depending on the distance between the horn and specimen, the specimen is subjected to various cavitation load. In most devices the frequency is close to $20 \mathrm{kHz}$. Similarly to the direct method, the peak-to-peak displacement amplitude may vary in a wide range. In cavitation tests showed in Ref. [15], the amplitude may be in the range from $25 \mu \mathrm{m}$ to $117 \mu \mathrm{m}$. With an increasing amplitude increases erosion rate. Similar effect was reached with lowering standoff distance.
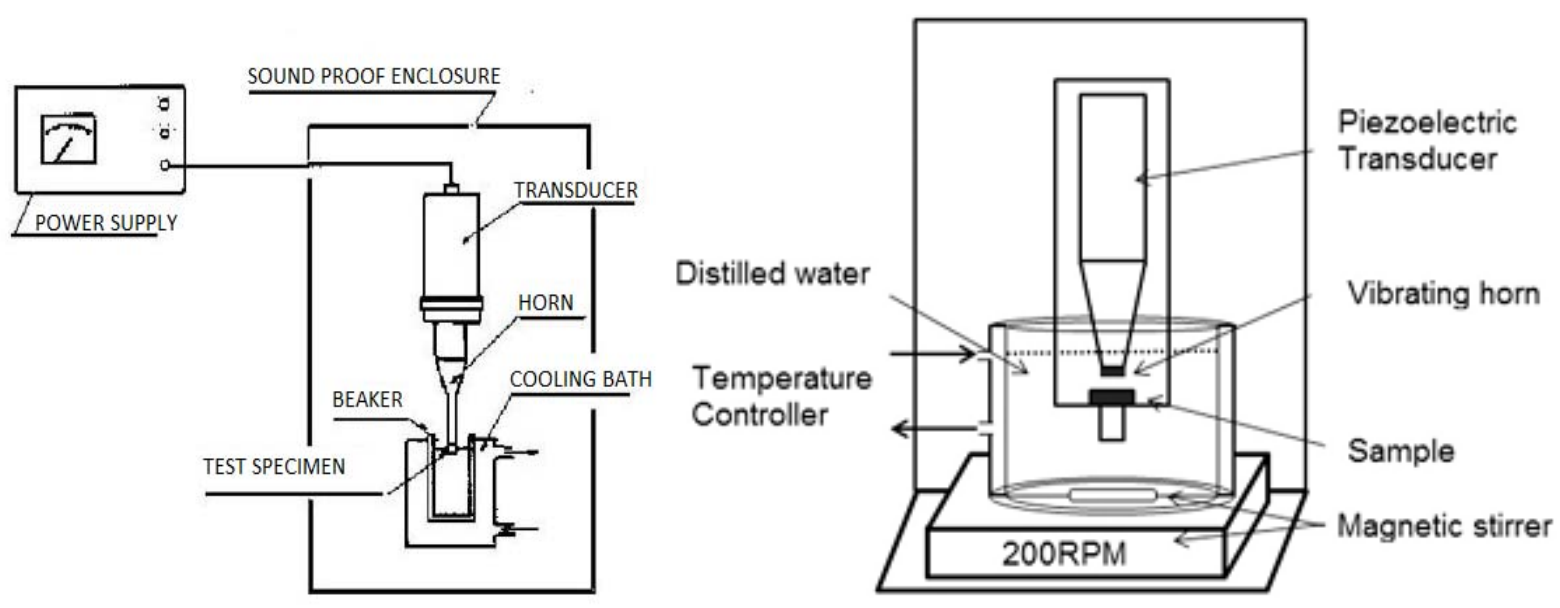

Fig. 3. Schematic of vibratory cavitation erosion apparatus; a) with a vibrating specimen, b) with stationary specimen 
The vibratory device has many advantages. It allows performing cavitation test in various liquids, including sea water or artificial sea water [21], blood [22] and liquids with solid particles [24]. The results of testing are repeatable. Due to generated intensive cavitation, the tests are not time consuming. In addition, the devices are small and very economical. However, Momma in his Ph.D thesis [25] pointed that vibratory apparatus generates different cavitation than that in flow devices, e.g. in hydraulic systems (pumps, turbines etc.).

\section{Cavitating liquid jets}

Applying the cavitating jet to the testing of cavitation erosion was proposed by Lichtarowicz in 1972 [26]. The jest is obtained by maintaining a high pressure difference across a nozzle and a specimen (Fig. 4). The test cell designed by Lichtarowicz was called his name and in 1995 was standardized in the ASTM Standards under G-134.

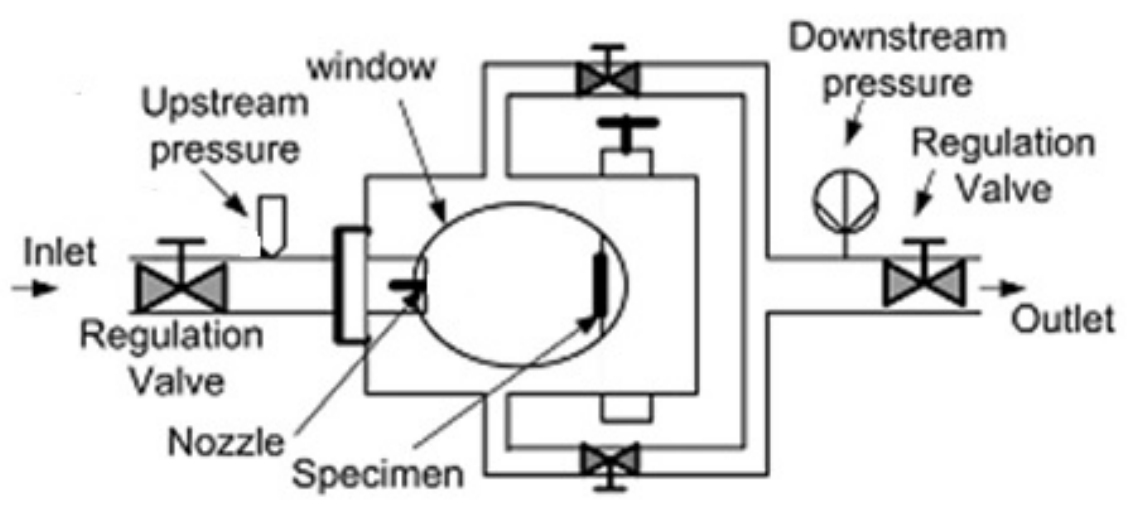

Fig.4. Scheme of cavitating jet cell [27], N-nozzle, S - specimen, $\mathrm{D}$ - distance between the specimen and nozzle

The scheme of Lichtarowicz's stand is presented in Fig.4. The system consists of two flows that allow controlling cavitation phenomenon. Invariable position of the sample allows stopping the tests at anytime, doing measurement of the sample and reinserting in handle continuing the tests. This test stand is commonly used in view of easy control of occurring phenomenon and easy match the intensity of cavitation [27-32]. Cavitation intensity is controlled by a type of a nozzle, jet velocity, the jet diameter and a stand-off distance that is defined from a nozzle to a specimen [25,31,32]. The jet pressure can achieve $450 \mathrm{MPa}$, jet velocity may exceed $250 \mathrm{~m} / \mathrm{s}$, the diameter of a nozzle may vary in a wide range similar to the distance between nozzle and sample [27]. For example in Ref. [29], the nozzle with diameter of $0.4,0.45,0.55,0.6 \mathrm{~mm}$ was used, while in Ref. [27], the nozzle diameter was used up to 2 $\mathrm{mm}$ was. Using the flow visualization devices, an influence of the nozzle geometry on the cavitation parameters, such as downstream pressure, jet velocity and pressure distribution in the test chamber, was studied [29,30]. A decrease of the nozzle diameter caused a decrease of the jet width, jet spreading angle and cavitation cloud density [30]. Wide analysis of an effect of the nozzle shape has performed by Soyama in Ref. [32]. He has investigated eight different geometries of test nozzles. According to Ref. [32], the nozzle geometry has an influence on the optimum standoff distance and erosion intensity, even though the other test parameters 
remains is the same. The maximum difference in the maximum erosion rate for the same material was more than $600 \%$. However, the relative cavitation erosion resistances of each tested material were independent of the nozzle geometry [31].

Next advantage of this apparatus is the uncomplicated control of the operating pressures to simulate a variety of cavitation conditions, which are relevant to the real flows, e.g. in ocean [33]. According to Lipej [28], this cavitation device enables imaging the real cavitation erosion process.

\section{Cavitation tunnels}

Cavitation tunnels, in opposition to earlier mentioned devices, are much bigger in size (Fig. 5) [34-36]. Cavitation is generated either using cavitators, e.g. a cylindrical bolts (Fig. 6a), wedges, a system of barricade/counter-barricade (Fig. 6b), or using a venturi effect (Fig. 7) [15,34-38]. Besides the mentioned cavitation inducers, there is also cavitation tunnels with hydrofoil that is put into a test section (Fig. 8) [39]. A test chamber often has a viewfinder that allows observing the flow and the cavitation cloud. Cavitation tunnels allow executing experiments that enable defining occurrence of various zones of cavitation phenomenon, and for that reason they often used for fundamental research on cavitation impingement and erosion. A test sample is usually placed in the wall of the canal - the place of occurrence of the cavitation phenomenon. Cavitation intensity depends on the geometry of the flow system in the test chamber, and also on the flow rate. In case of using the system of barricades, the flow geometry is easily modified by regulation of slot width. The flow velocity depends on the inlet and outlet pressure that are controlled using valves located before and after the test chamber. According to Ref. [15], the liquid velocity during cavitation test may be in the range from $2.4 \mathrm{~m} / \mathrm{s}$ to $30 \mathrm{~m} / \mathrm{s}$, this corresponds to the range from 28 to $45 \mathrm{~m} / \mathrm{s}$ of local liquid velocity. Flow velocity and the shape of cavitator influence the erosion rate. Based on cavitation tests $[15,34]$, the least intensive cavitation erosion was reached in a tunnel with wedge cavitator, while the most intensive cavitation in a tunnel with a cylindrical bolt. The flow velocity can causes increase of aggressiveness cavitation erosion what contributed to design high-speed cavitation tunnel, where the maximum pressure can achieve $4 \mathrm{MPa}$ and the flow velocity about $90 \mathrm{~m} / \mathrm{s}$ [13]. Temperature control at constant value during long tests provides a heat exchanger. The high-speed cavitation tunnel allows to preserve the cavitation number during the modification of flow velocity. Among the high-speed cavitation tunnels can list tunnels: venturi with or without a central body, cylindrical specimen spanning the tunnel or radial divergent [35]. 


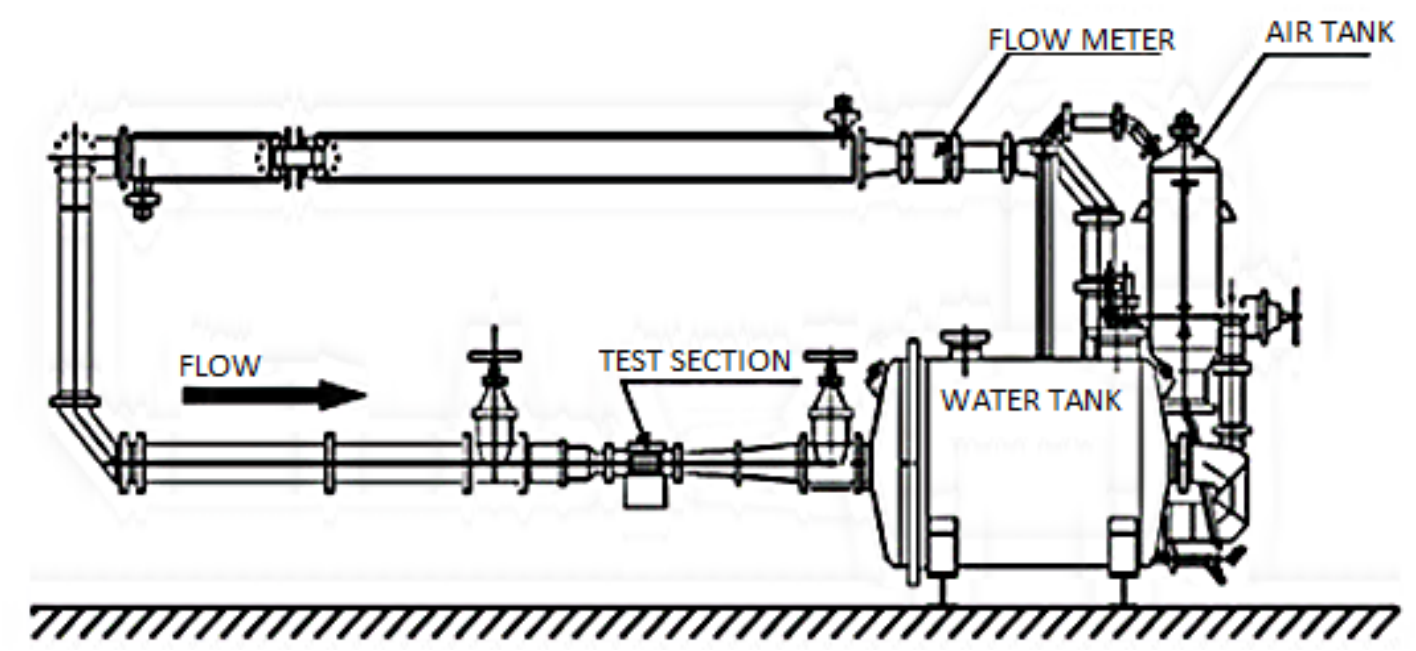

Fig. 5. Cavitation tunnel. Length of the test section- $500 \mathrm{~mm}$, high $-100 \mathrm{~m}$, wide $50 \mathrm{~mm}$ [21] $\mathrm{m} / \mathrm{s}$.

The venture tunnel/test section/ in Ref. [35] (Fig.7) allowed to obtain a flow rate of 50

The results from the tests were used to compare the results obtained on the vibratory apparatus. Was observed, that the incubation time was in correlation with the cavitation resistance for both facilities. The cavitation intensity measured as maximum depth penetration rate (MDPR) was few times greater in the vibratory apparatus. Venturi tests shown that with increasing temperature and velocity MDPR is also increasing.

a)
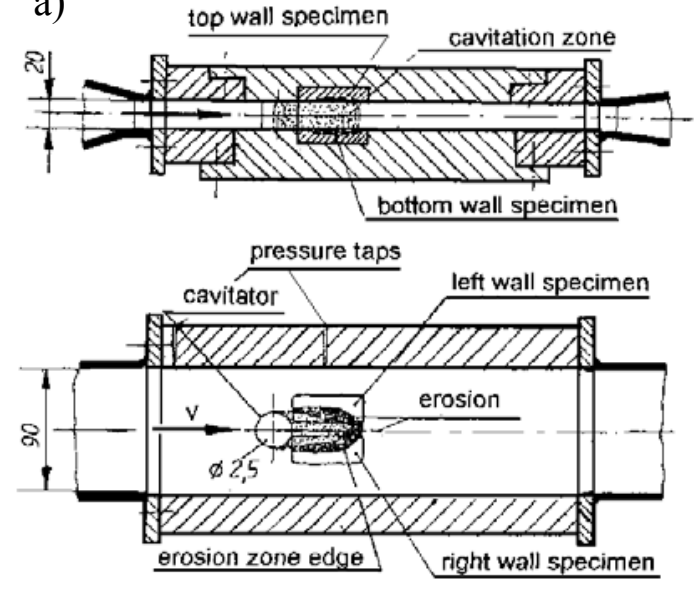

b)

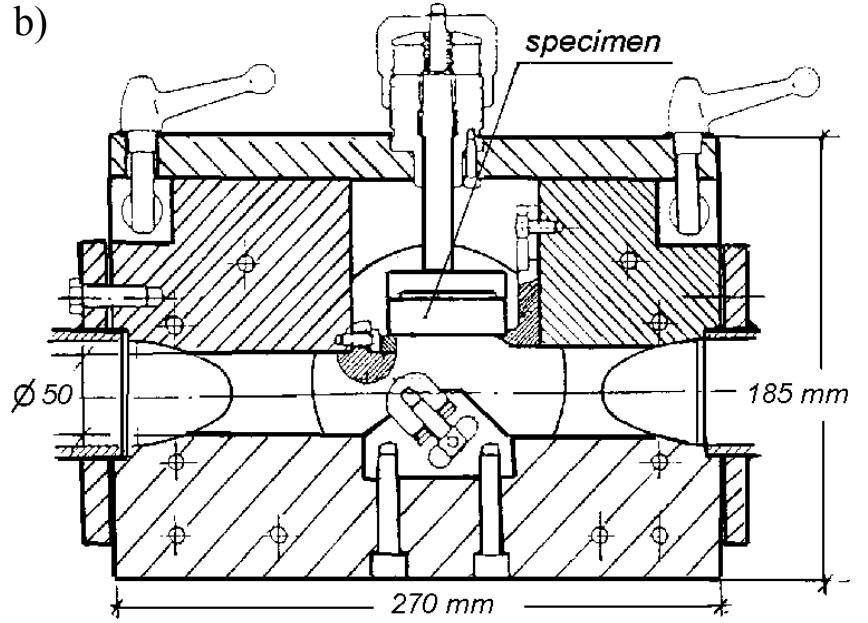

Fig. 6. Test chamber with a cylindrical cavitator (a) and test chamber with a system of barricades(b) [15] 


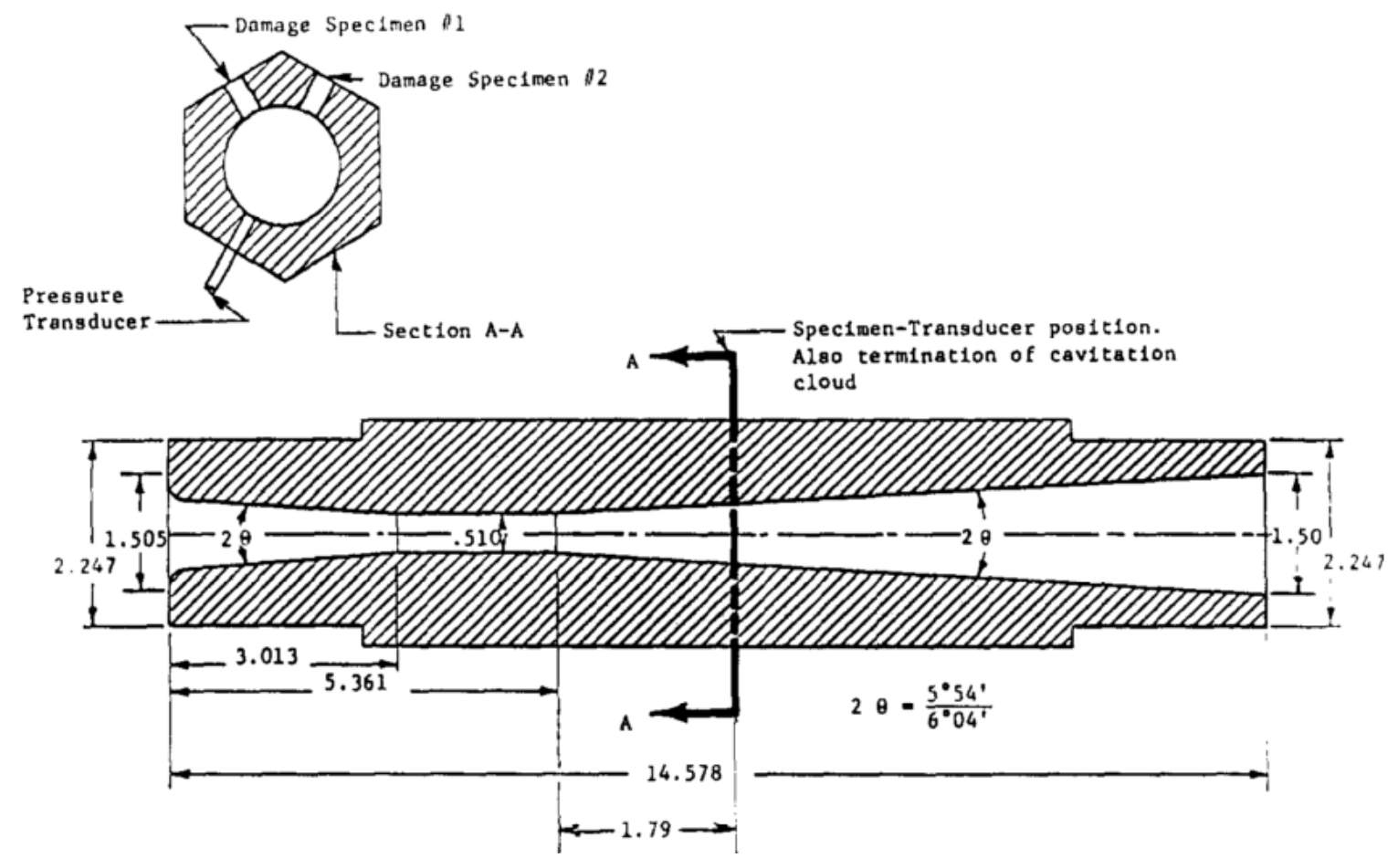

Fig. 7. Venturi chamber [15]

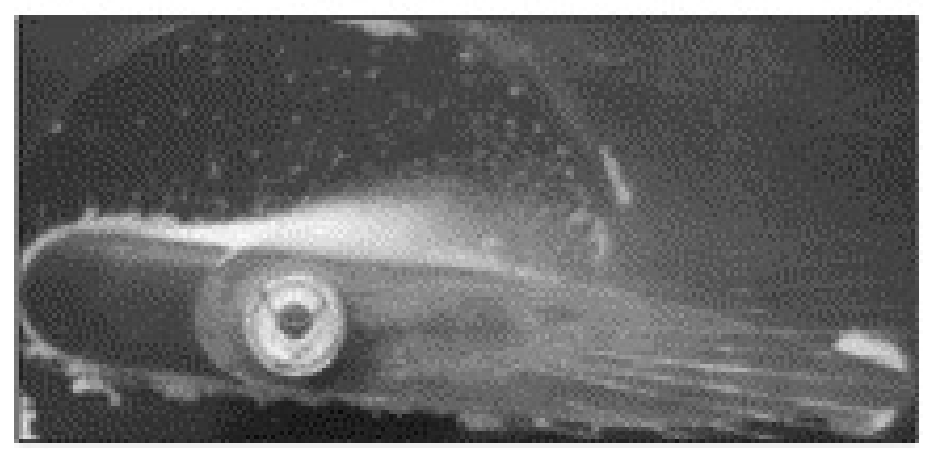

Fig. 8. Chamber with hydrofoil [39]

Rotating disc apparatus

The rotating disc apparatus allows reflecting the conditions of real flow in vortex hydraulic machines [37,40-43]. An example of a rotating disc rig and a cover with specimen holders are shown below in Fig. 8. Cavitation is generated either by holes or by cylindrical bolts located on the surface of rotating disc, so cavitation intensity can be either very weak or very severe, respectively. Samples of tested material can be placed on the disc (Fig. 9) or in special holes drilled in the disc [34,35]. The disc construction allows to mount several samples and observe the phenomenon via an observation window.

According to Ref. [12], volume loss of austenitic stainless steel X6CrNiTi18-10 $(1 \mathrm{H} 18 \mathrm{~N} 9 \mathrm{~T})$ in erosion test performed in a rotating disc rig with cylindrical bolts as cavitators was over two times bigger than that in a vibratory rig designed according to ASTM G-32 Standard. 


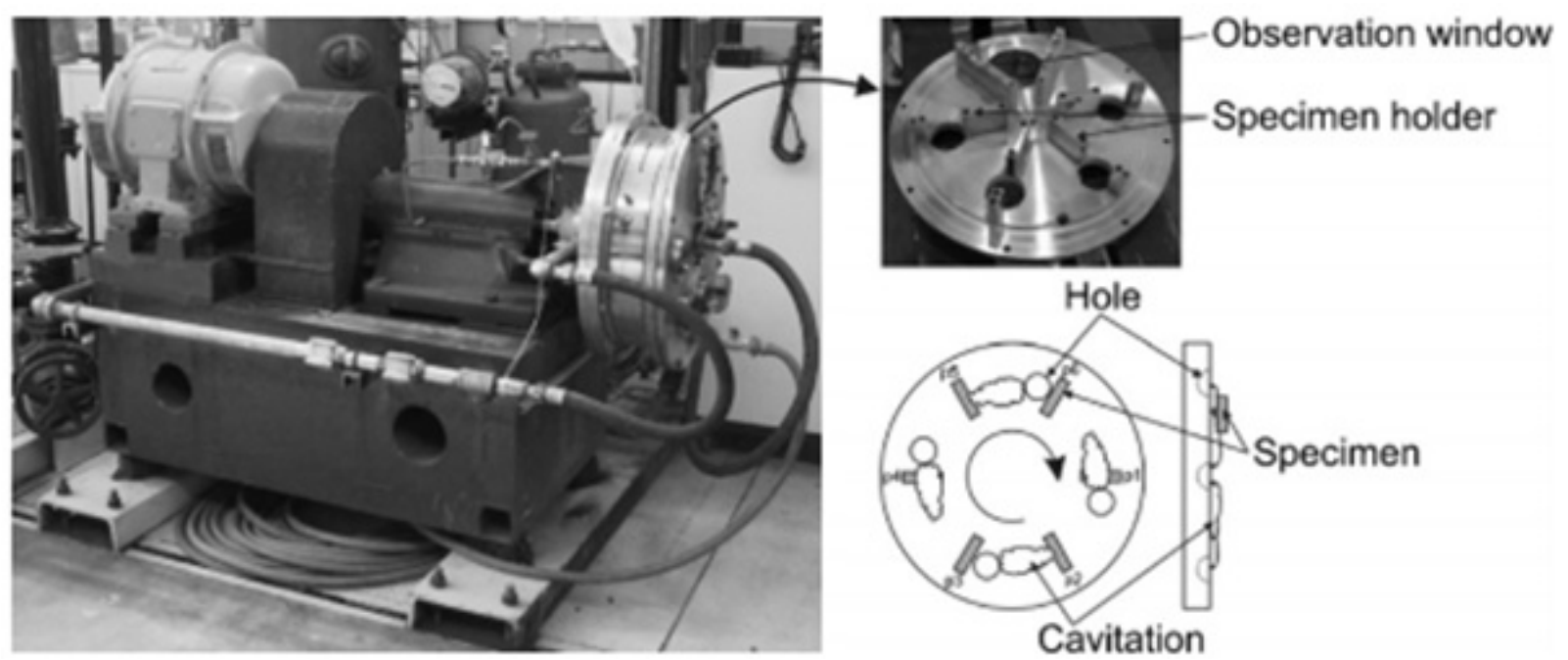

Fig. 9. Rotating disc (left) and cover with specimens holders and cavitation (right) [35]

In Ref. [42] reported that the peripheral velocity depends on specimen position on the rotating disc, which also affected mass loss of the samples. Mass loss increasing with the size of the sample surface, but with decreasing peripheral velocities the mass loss was also decreasing.

\section{CONCLUSION}

In the paper four main types of cavitation erosion stand have been presented. Two of them: the vibratory and cavitating jet apparatus are standardized and described in the International ASTM Standards. Many of the apparatus are modified to reproduce the conditions prevailing in cavitation erosion devices. Each modification of the construction allows to examine the behavior of the material in different forms of cavitation. The differences in the test device design and in testing condition cause the differences in the cavitation resistance of tested materials. Using the cavitating jet cell the rate of erosion is comparable with the results obtained in cavitation tunnels. An important aspect is also the standardization of the position which enables not only easy control of tests conditions, but also the speed of erosion. This would allow a preliminary determination the resistance of the material subjected to the specified cavitation loads.

\section{REFERENCES}

1. Karimi A., Martin J.L.: Cavitation erosion of materials. International Metals Reviews 31 (1986), pp. 1-26.

2. Hubballi V., Sondur V.: A Review on the prediction of cavitation erosion inception in hydraulic control Valves. International Journal of Emerging Technology and Advanced Engineering 3 (2013), 110-119.

3. Bourne N.K.: On impacting liquid jets and drops onto polymethylmethacrylate targets, Proc. R. Soc. A (2005) 461, 1129-1145

4. Kuiper G.: Cavitation research and ship propeller design, Applied Scientific Research (1998) 58, $33-50$. 
5. Dular M., Stoffel B., Sirok B., Development of a cavitation erosion model. Wear 261 (2006) 642655.

6. Brennen Ch.E.: Cavitation and bubble Dynamics. Oxford University Press, New York, 1977.

7. Śniegocka B., Szkodo M., Chmiel J.: Influence of spatial structures of 316L stainless steel on its cavitation resistance. Solid State Phenomena 225 (2015) 109-114.

8. Wójs K.: Kawitacja w cieczach o różnych właściwościach reologicznych. A. Kaczak [ed.], Oficyna Wydawnicza Politechniki Wrocławskiej, Wrocław, 2004. (in Polish)

9. Knapp R. T., Daily J. W., Hammit F.G.: Cavitation, McGraw-Hill, New York 1970.

10. Lauterborn W., Bolle H.: Experimental investigations of cavitation-bubble collapse in the neighbourhood of a solid boundary. J. Fluid Mech. 72, part 2 (1975) 391-399.

11. Lindau O., Lauterborn W.: Cinematographic observation of the collapse and rebound of a laserproduced cavitation bubble near a wall, J. Fluid Mech. (2003), vol. 479 327-348.

12. Philipp, A., Lauterborn, W.: Cavitation erosion by single laser-produced bubbles. J. Fluid Mech. 361 (1998) 75-116.

13. Kim K., Chahine G. L., Franc J.-P., Karimi A.: Advanced Experimental and Numerical Techniques for Cavitation Erosion Prediction. Kim K., Chahine G. L., Franc J.-P., Karimi A. [eds], Springer International Publishing, Dordrecht, 2014.

14. Laterborn W.: Cavitation and Coherent Optics, 1980, Proc. Of the $1^{\text {st }}$. International Cnference, Göttingen, Fed. Rep. Of Germany, 1979, 3-12.

15. Steller J., Gireń G.: International Cavitation Erosion Test. Final report. Zeszty Naukowe IMP PAN, Gdańsk, 2015.

16. Jasionowski R.: Badania odporności materiałów na erozję kawitacyjną, Cz. I Stanowiska badawcze. Zeszyty Naukowe WSM Szczecin nr 72, Szczecin 2003. (in Polish)

17. Kmieć M., Karpiński B., Szkodo M.: Cavitation erosion of P110 steel in different drilling muds. Advances in Materials Science 16 (2016) 57-66.

18. Li Z., Han J., Lu J., Zhou J., Chen J.: Vibratory cavitation erosion behavior of AISI 304 stainless steel in water at elevated temperatures. Wear 321 (2014) 33-37.

19. Mitelea I., Bordeasu I., Pelle M., Craciunescu C.: Ultrasonic cavitation erosion of nodular cast iron with ferrite-pearlite microstructure. Ultrasonics Sonochemistry 23 (2015) 385-390.

20. Niederhofer P., Huth S.: Cavitation erosion resistance of high intersitial $\mathrm{CrMnCN}$ austenitic stainless steel. Wear 301 (2013) 457-466.

21. Kim S-J., Lee S-J., Chong S-O.: Electrochemical characteristics under cavitation-erosion for STS 316L in seawater. Materials Research Bulletin 58 (2014) 244-247

22. Wu J-h., Wang Y., Ma F., Gou W-j. Cavitation erosion in bloods. Journal of Hydrodynamics, Ser. B, 29 (2017) 724-727.

23. Gottardi G., Tocci M., Montesano L., Pola A.: Cavitation erosion behaviour of an innovative aluminium alloy for Hybrid Aluminium Forging, Wear 394-395 (2018) 1-10.

24. Hu H.X., Zheng Y.G.: The effect of sand particle concentrations on the vibratory cavitation erosion. Wear 384-385 (2017) 95-105.

25. Momma T.: Cavitation Loading and Erosion Produced by a Cavitating Jet. $\mathrm{PhD}$ thesis, Nottingham, 1991.

26. Lichtarowicz, A. and Sakkejha, F., "Cutting with Cavitating Jets," Paper G6, Proc. 1st Int. Symp. Jet Cutting Tech., BHRA, Coventry, UK, April 1972 
27. Hutli E., Nedeljkovic M.S., Radovic N.A., Bonyár A., The relation between the high speed submerged cavitating jet behaviour and the cavitation erosion process, International Journal of Multiphase Flow 83 (2016) 27-38.

28. Lipej A.: Cavitation and dynamic problems. S. Muhic (ed), 6th IAHR meeting of the Working Group, IAHRWG 2015, Slovenia, September 9-11, 2015.

29. Thapa B., Chaudhary P., Dahlhaug O., Upadhyay P.: Study of combined effect of sand erosion and cavitation in hydraulic turbines. Proc. International Conference on Small Hydropower, Sri Lanka, 2007, 22-24.

30. Hutli E. A. F., Nedeljković M.S.: Investigation of a Submerged Cavitation Jet Behaviour: Part One- The Phenomenon, Detection Technique and Sono-Luminescence. FME Transactions vol. 35 (2007) 113-119.

31. Hutli E. A. F., Nedeljković M.S.: Investigation of a Submerged Cavitation Jet Behaviour: Part Two - Influences of operating conditiond, geometrical parameters and arrangements of detection system. FME Transactions vol. 35 (2007) 121-128.

32. Soyama H.: Effect of nozzle geometry on a standard cavitation erosion test using a cavitating jet, Wear 297 (2013) 895-902

33. Peng Ch., Tian S., Li G.: Joint experiments of cavitation jet: High-speed visualization and erosion test. Ocean Engineering 149 (2018) 1-13.

34. Steller J.: International Cavitation Erosion Test and quantitative assessment of material resistance to cavitation. Wear 233-235 (1999) $51-64$.

35. Veerabhadra R., Syamala Rao B., Buckley D.H.: Size scale effect in cavitation erosion. Proc. Cavitation and Multiphase Flow Forum, Louisiana, 1984, 11-17.

36. Dular M., Petkovšek M., On the mechanisms of cavitation erosion - Coupling high speed videos to damage patterns, Experimental Thermal and Fluid Science 68 (2015) 359-370.

37. He J., Hammitt F. G.: Comparision of cavitation erosion test results from venturi and vibratory facilities. Wear vol. 76 (1982) 269-292.

38. Krella A.: The experimental resistance parameter for TiN coating to cavitation action. Advances in Materials Science 10 (23) (2010) 4-18

39. Dular M., Stoffel B., Širok B.: Development of a cavitation erosion model. Wear 261 (2006) 42655.

40. Hart D., Whale D.: A review of cavitation-erosion resistance weld surfacing alloys for hydroturbines. Eutectic Cast. Pty. Ltd. (2007) 15-30.

41. Mann B.S.: Boronizing of cast martensitic chromium nickel stainless steel and its abrasion and cavitation-erosion behavior. Wear v.208 (1997), 125-131.

42. Bazanini G., Bressan J. D., Klems M.A.: Cavitation erosion wear of metallic specimens using the new compact rotating disk device. Thermal Engineering Vol. 7 (2008), 31-36.

43. Rashed M.K., Abdulbari H.A., Salled M.A., Ismail M.H.: Rotating disc apparatus: types, developments and future applications. Modern Applied Science 10 (2016) 198-229. 